\author{
Professor JavierREIG-MULLOR, PhD \\ E-mail: javier.reig@umh.es \\ Universitas Miguel Hernandez \\ Professor David PLA-SANTAMARIA, PhD \\ E-mail: dplasan@upv.es \\ Universitat Politècnica de València \\ Professor Ana GARCIA-BERNABEU, PhD \\ E-mail: angarber@esp.upv.es \\ Universitat Politècnica de València \\ Professor Francisco SALAS-MOLINA, PhD \\ E-mail: Francisco.salas.molina@gmail.com \\ Universitat de València
}

\title{
NOVEL DISTANCE MEASURE IN FUZZY TOPSIS TO IMPROVE RANKING PROCESS: AN APPLICATION TO THE SPANISH GROCERY INDUSTRY
}

\begin{abstract}
In this paper, a novel approach to measuring distances between triangular fuzzy numbers is suggested. This new method allows to improve sensitivity of results. We also apply several methods together with our proposal to rank the financial performance of Spanish grocery store companies. Methods such as Fuzzy Analytic Network Process (FANP) and fuzzy TOPSIS are integrated in the proposed model. The weights for criteria and subcriteria are computed based on the judgments of experts using FANP. Then, these weights and financial ratios are inputs to the fuzzy TOPSIS method to rank the companies. In the case of fuzzy TOPSIS, several distance measures are applied and a novel measure based on the Spearman distance is introduced. We conclude that results applying fuzzy TOPSIS depend on the selected distance and therefore the decision maker has to apply different distance measures to improve conclusions. Finally, a sensitivity analysis of the analyzed measures has been performed.

Keywords: financial performance, fuzzy numbers, fuzzy ANP, fuzzy TOPSIS, Spearman distance.

\section{JEL Classification: D81,G30}

\section{Introduction}

Financial performance is central to the survival of businesses, especially in the grocery sector, which is characterized by a rising competition, reduced sales margins and limited creation of added value. Specifically, this study focuses on the evaluation of financial performance in the main companies of this sector in Spain,
\end{abstract}

DOI: 10.24818/18423264/53.1.19.08 
Javier Reig-Mullor, David Pla-Santamaria, Ana García-Bernabeu, Francisco Salas-Molina

i.e., those with sales in excess of 1,500 million Euros. The analyzed period spans 5 years, from 2010 to 2014.

In our work, the criteria to evaluate financial performance of grocery store companies will be financial ratios. This kind of information is widely referenced in the literature when dealing with a broad spectrum of problems.

The financial ratios used in this work come from the three main financial statements (balance sheet, income statement and cash-flow). In fact, these ratios are usually classified into some categories, since accounting experts claim that financial ratios within a cluster are partially similar. We divide financial ratios of grocery store companies into the following categories: Liquidity, Solvency, Activity, Profitability and Growth.

Over the last years, the Analytic Hierarchy Process (AHP), developed by Saaty (1980), has become one of the most widely used MCDM tools in the resolution of complex decision making problems. All the pairwise comparisons generated by the relative weights of the criteria, which appear in the intermediate stages of AHP, represent judgments made by decision makers (DMs). These are based on knowledge and information that DMs have about the problem, which means that the pairwise comparisons are imbued with subjectivity in the interpretation and assessment of the problem. Therefore, DMs personal viewpoints can profoundly affect the final results (Chai, Liu, and Ngai, 2013).

Since many decision-making problems involve interaction of various items and moreover, high-level items occasionally depend on low-level items, there are problems that cannot be structured hierarchically. This problem arises in the hierarchical structure proposed in this work. Criteria and subcriteria have a dependence relationship among each other; for instance, the Solvency criterion has a relevant connection with the company's Liquidity, or Profitability depends on Activity. Similarly, in the case of subcriteria, ROE depends on the ROA generated by the company. Therefore, since AHP cannot be applied in this case, we propose using a methodology which allows the representation of dependence on criteria and subcriteria. In this respect, Saaty proposed ANP to solve the problem of dependence among criteria.

Saaty (1996) introduced ANP as an extension of the AHP methodology. ANP is a mathematical procedure that allows the researcher to deal with all kinds of dependences. This model achieves its goal by replacing hierarchies with networks (Saaty, 1996). Besides, this approach is useful for complex interrelationships among decision criteria. It replaces hierarchies with networks where the relationships between factors are hardly characterized as upper or lower, dominant or subordinate, direct or indirect. in these problems, a hierarchical structure with a linear top-to-bottom form cannot represent a complex system.

The ANP decision model is ineffective in dealing with the inherent subjectivity in judgment during the pairwise comparison process (Tavana et al., 
Novel Distance Measure in Fuzzy TOPSIS to Improve Ranking Process: An Application to the Spanish Grocery Industry

2016). Using a scale of 1-9 to represent the verbal judgment in pairwise comparisons is not considering the uncertainty associated with the mapping of the expert judgment to a discrete number. In real world problems, incomplete information or knowledge, complexity and uncertainty could drive the decision makers to be uncertain about their own level of preference (Sansalvador and Brotons, 2017). These scenarios could happen when an optimal Project is being selected and evaluated.

Regarding dissemination and use of FANP, according to Afful et al. (2017) 266 papers mentioning FANP were published in the period 2000-2015. Specifically, Mardani et al. (2015) include 26 papers in which this methodology is used over the period 1994-2014.

Once the weights have been determined through FANP method and the financial ratios have been computed, we will establish the ranking for the companies using fuzzy TOPSIS (Liang, 1999) method, which is a generalization of TOPSIS on fuzzy environment.

According to Mardani et al. (2015), 79 papers applying Fuzzy TOPSIS method alone or combined with other methods were published between years 1994 and 2014, whereas in Afful et al. (2017) this methodology is cited 1102 times in the period 2000-2015.

The paper is organized as follows. In Section 2, the bases of fuzzy sets and fuzzy numbers are shown, with particular reference to the so-called triangular number (TN). In Section 3, we thoroughly examine FAHP/FANP and the Fuzzy Preference Programming (FPP) method proposed by Mikhailov (2003), which includes triangular numbers (TN). Fuzzy TOPSIS methods are introduced in Section 4, where the main contribution of this work is presented. We propose a novel distance measure based on Spearman distance to be applied in the computing phase of fuzzy TOPSIS, which improves the ranking process. Section 5 develops a practical application based on the financial performance for Spanish grocery store companies.

\section{Fuzzy sets and fuzzy numbers}

As mentioned in the previous section, it is of utmost importance to consider uncertainty and subjectivity in any quantification process, since they determine the In order to explain the difference between fuzziness and randomness, Zadeh (1965) introduces the concept of fuzzy sets.

Definition 1: A fuzzy set is set of objects with a continuum of grades of membership, this set being characterized by a membership function (characteristic function) which assigns to each object a grade of membership ranging between zero and one.

The idea of fuzzy sets involves an adequate starting point for the 
Javier Reig-Mullor, David Pla-Santamaria, Ana García-Bernabeu, Francisco Salas-Molina

construction of a conceptual framework which has parallels with that used in ordinary sets. This theory provides a natural path for problem management, where imprecision and the lack of defining and certain criteria of group membership lead to the appearance of uncertain variables. A type of fuzzy sets, especially aimed at economic problem resolution where uncertainty and subjectivity are present, is fuzzy numbers.

Definition 2: A fuzzy number is a fuzzy set defined on the domain of real numbers R, which satisfies the conditions of convexity and normality. Therefore, it is necessary to introduce the concepts of convex and normal fuzzy set into our analysis.

Definition 3: Let $\mathrm{X}$ be a set of points or objects, and $\mathrm{x}$ a generic element of X. $\tilde{A}$ is a convex fuzzy set if and only if (Zadeh, 1965):

$\mu_{\tilde{\mathrm{A}}}\left[\lambda \mathrm{x}_{1}+\left(1-\lambda \mathrm{x}_{2}\right)\right] \geq \operatorname{Min}\left[\mu_{\tilde{\mathrm{A}}}\left(\mathrm{x}_{1}\right), \mu_{\tilde{\mathrm{A}}}\left(\mathrm{x}_{2}\right)\right] \quad \forall \mathrm{x}_{1}, \mathrm{x}_{2} \epsilon \mathrm{X} ; \forall \lambda \in[0,1]$

Definition 4: $\tilde{A}$ is a normal fuzzy set if and only if: $\operatorname{MAXx} \mu_{\tilde{A}}(x)=1$

That is, a fuzzy set is convex when the slope decreases because of shifts to the left or the right of the maximum value of the membership function; and it is normal if at least an element of the set takes maximum value 1 in the membership function. number,

In what follows, we will define a type of fuzzy number called triangular

Definition 5: $T \tilde{A}=\left(a^{1}, a^{2}, a^{3}\right)$, where $a^{1} \leq a^{2} \leq a^{3} \in \mathrm{X}$. Its membership function is given by:

$$
\mu_{\tilde{A}}(x)= \begin{cases}\frac{x-a^{1}}{a^{2}-a^{1}}, a^{1} \leq x \leq a^{2} \\ \frac{a^{3}-x}{a^{3}-a^{2}}, a^{2} \leq x \leq a^{3} \\ 0 \quad \text { Otherwise }\end{cases}
$$

\section{Calculation of Criteria Weights}

\subsection{Fuzzy Analytic Hierarchy Process (FAHP)}

FAHP represents an approach to choose alternatives and solve problems using fuzzy set theory to express the uncertain comparison of opinions with fuzzy numbers and the AHP method. The main steps in FAHP are the following: 
Novel Distance Measure in Fuzzy TOPSIS to Improve Ranking Process: An Application to the Spanish Grocery Industry

(1) The first step is to transform a complex decision making problem into a hierarchical structure. This is similar to conventional AHP.

(2) To develop pairwise fuzzy comparison matrices. Consider a prioritization problem with $n$ elements, where pairwise fuzzy comparisons are represented by fuzzy numbers. In AHP, each set of comparisons for a level requires $n(n-1) / 2$ judgments, which are used to construct a positive fuzzy reciprocal comparison matrix $\tilde{A}=\left\{\tilde{a}_{i j}\right\}$ such that:

$$
\tilde{A}=\left\{\tilde{a}_{i j}\right\}=\left(\begin{array}{ccc}
\tilde{a}_{11} & \cdots & \tilde{a}_{1 t} \\
\vdots & \ddots & \vdots \\
\tilde{a}_{t 1} & \cdots & \tilde{a}_{t t}
\end{array}\right)
$$

Let $K$ decision makers involved in the study: they make pairwise comparisons of $n$ elements. As a result of the pairwise comparison, we get a set of $K$ matrices $\tilde{A}_{k}=\left\{\tilde{a}_{i j k}\right\}$, where $T \tilde{A}_{i j k}=\left(a_{i j k}^{1}, a_{i j k}^{2}, a_{i j k}^{3}\right)$ represents the relative importance of element $i$ to $j$, as assessed by expert $k$. The triangular numbers in the group judgment matrix can be computed through the following equation (Chen, Hsieh and Do, 2015):

$a_{i j}^{1}=\min _{k=1 \ldots K}\left(a_{i j k}^{1}\right) \quad a_{i j}^{2}=\sqrt[k]{\prod_{k=1}^{K} a_{i j k}^{2}} \quad a_{i j}^{3}=\max _{k=1 \ldots k}\left(a_{i j k}^{3}\right)$

The linguistic scale and underlying triangular numbers are illustrated in Table 1 based on Rezaie et al. (2014).

Table 1. The linguistic scale and underlying triangular number

\begin{tabular}{|c|l|c|}
\hline Fuzzy number & \multicolumn{1}{|c|}{ Linguistic Scales } & Scale of fuzzy numbers \\
\hline$\tilde{1}$ & Equally important & $(1,1,1)$ \\
\hline$\tilde{3}$ & Weakly important & $(2,3,4)$ \\
\hline$\tilde{5}$ & Essentially important & $(4,5,6)$ \\
\hline$\tilde{7}$ & Very strongly important & $(6,7,8)$ \\
\hline$\tilde{9}$ & Absolutely important & $(x-1,10)$ \\
\hline$\tilde{2}, \tilde{4}, \tilde{6}, \tilde{8}$ & Intermediate values $(\tilde{x})$ & $\left(\frac{1}{x+1}, \frac{1}{x}, \frac{1}{x-1}\right)$ \\
\hline$\frac{1}{\tilde{x}}$ & Between two adjacent judgments & \\
\hline
\end{tabular}


Javier Reig-Mullor, David Pla-Santamaria, Ana García-Bernabeu, Francisco Salas-Molina

(3) To control coherence and resulting priorities. This step checks consistency and obtains priorities from the pairwise fuzzy matrices.

(4) To aggregate priorities and classification of alternatives. By applying a simple weighted sum, the local priorities obtained in the different levels of the hierarchy of decisions are aggregated. The obtained global priorities yield the final ranking and the selection of the best one.

Mikhailov (2003) proposed a Fuzzy Preference Programming (FPP) to derive priorities from the fuzzy comparison judgments that solves some of the problems of the fuzzy prioritization methods. This approach allows an incomplete set of fuzzy judgments to derive priorities. Moreover, the proposed approach is invariant to the specific shape of the fuzzy sets used to represent opinions (Javanbarg et al., 2012). We have specifically selected Mikhailov's methodology, since it allows us to evaluate consistency of decision makers' opinions through the so-called $\lambda$ or "index of consistency".

Using $\alpha$-cuts, initial fuzzy opinions may be transformed into a set of interval judgments. The method is employed to turn the FPP priority allocation problem into a fuzzy program that can derive clear priorities from interval judgments, which corresponds to each $\alpha$-level cut, thus removing the need for an additional fuzzy classification procedure.

Let us suppose that a fuzzy judgment matrix $\tilde{A}=\left\{\tilde{a}_{i j}\right\}$ is built as in (2). The elements of the pairwise fuzzy comparison matrix are represented by Triangular Numbers $T \tilde{a}_{i j}=\left(a_{i j}^{1}, a_{i j}^{2}, a_{i j}^{3}\right)$, where $i, j=1, \ldots t$. Besides,

$$
\begin{aligned}
& \text { If } i \neq j, a_{i j}^{1}<a_{i j}^{2}<a_{i j}^{3} \\
& \text { If } i=j, \tilde{a}_{i j}=\tilde{a}_{j i}=(1,1,1) \\
& \text { where } w=\left(w_{1}, w_{2}, \ldots, w_{t}\right)^{T} \text { is the vector of crisp priorities. }
\end{aligned}
$$

The nonlinear program developed by Mikhailov to obtain the weight for each criterion is:

Maximize $\lambda$

Subject to

$$
\begin{aligned}
& \left(a_{i j}^{2}-a_{i j}^{1}\right) \lambda w_{j}-w_{i}+a_{i j}^{1} w_{j} \leq 0 \\
& \left(a_{i j}^{3}-a_{i j}^{2}\right) \lambda w_{j}+w_{i}-a_{i j}^{3} w_{j} \leq 0 \\
& \sum_{k=1}^{t} w_{k}=1 ; w_{k}>0 ; k=1,2, \ldots, t \\
& i=1,2, \ldots, t-1 ; j=1,2,3, \ldots, t ; j>i
\end{aligned}
$$


Novel Distance Measure in Fuzzy TOPSIS to Improve Ranking Process: An Application to the Spanish Grocery Industry

The optimal value $\lambda^{*}$ is "the consistency index". This value is used to measure the level of satisfaction of the optimal priority vector $w^{*}$. When $\lambda^{*}$ is positive, all the solution coefficients fully satisfy fuzzy opinions, which means that the initial set of fuzzy judgments is rather consistent. A negative value of $\lambda^{*}$ shows that the fuzzy judgments are strongly inconsistent, that is, the optimal value of $\lambda^{*}$ can be used as a measure of the consistency of the initial set of fuzzy judgments.

\subsection{Fuzzy Analytic Network Process (FANP)}

This procedure is useful to set the weights when there is interdependence among criteria. The composite weights of two interdependent levels are elicited constructing a supermatrix for FANP. The pairwise comparisons of items are linguistically expressed in Table 1 , these lingual expressions being represented by TFN. 2015):

The fuzzy ANP approach is applied as follows (Yu, Keng and Chen,

(1) The weight vectors for each matrix are computed and placed in the supermatrix.

(2) Adjust the supermatrix to conform to the principle of column stochastic and turn it into a weighted supermatrix. When the supermatrix is raised to high powers, it will converge.

(3) Compute global weights of subcriteria by multiplying the interdependent weights of the subcriteria with those of the criterion to which it belongs.

\section{Ranking alternatives}

In this work, the ranking MCDM method and improved fuzzy TOPSIS are applied to rank the Spanish grocery store firms, which allows us to perform a sensitivity analysis of the obtained results by evaluating the different methodologies.

Fuzzy TOPSIS (Liang, 1999) is a generalization of TOPSIS in fuzzy environment. The algorithm of the fuzzy TOPSIS method has six main steps, as follows:

Step 1: Let $\tilde{V}_{i j}=\left(v_{i j}^{1}, v_{i j}^{2}, v_{i j}^{3}\right)$ be fuzzy data for alternative $i$ on criteria $j$, where $i=1, \ldots, n ; j=1, \ldots, J$. Then, $\left[\tilde{V}_{i 1}, \tilde{V}_{i 2,} \ldots, \tilde{V}_{i J}\right]$ denotes performance matrix of alternative $A_{i}$ on all criteria, where $i=1, \ldots, n$. The triangular numbers $\tilde{V}_{i j}=\left(v_{i j}^{1}, v_{i j}^{2}, v_{i j}^{3}\right)$ can be obtained by using the following equation (Wang, 2014). 
Javier Reig-Mullor, David Pla-Santamaria, Ana García-Bernabeu, Francisco Salas-Molina

$$
v_{i j}^{1}=\min _{t=1 \ldots T}\left(v_{i j t}\right) \quad v_{i j}^{2}=\frac{1}{T}\left(\sum_{t=1}^{T} v_{i j t}\right) \quad v_{i j}^{3}=\max _{t=1 \ldots T}\left(v_{i j t}\right)
$$

where $t=1, \ldots, T, T$ corresponding to the number of periods under consideration.

Step 2: Construct the weighted normalized fuzzy decision matrix $\left[\tilde{R}_{n x J}\right]$

$$
\tilde{R}_{i j}=W_{j} \otimes \tilde{V}_{i j}, \quad i=1, \ldots, n ; j=1, \ldots, J
$$

Step 3: Calculate by MIN and MAX operations, anti-ideal solution $\tilde{R}^{-}$, and ideal solution $\tilde{R}^{+}$, of the $n$ alternatives. Let

$$
\begin{aligned}
\tilde{R}^{-} & =\left[\tilde{R}_{1}^{-}, \tilde{R}_{2}^{-}, \ldots, \tilde{R}_{J}^{-}\right] \mathrm{j}=1,2, \ldots, \mathrm{J} \\
\tilde{R}^{+} & =\left[\tilde{R}_{1}^{+}, \tilde{R}_{2}^{+}, \ldots, \tilde{R}_{J}^{+}\right] \mathrm{j}=1,2, \ldots, \mathrm{J}
\end{aligned}
$$

Where

$$
\tilde{R}_{j}^{-}=\operatorname{Min}_{1 \leq i \leq n}\left\{\tilde{R}_{i j}\right\}=\left(\operatorname{Min}_{1 \leq i \leq n}\left\{r_{j}^{1}\right\}, \operatorname{Min}_{1 \leq i \leq n}\left\{r_{j}^{2}\right\}, \operatorname{Min}_{1 \leq i \leq n}\left\{r_{j}^{3}\right\}\right)=\left(r_{j}^{1-}, r_{j}^{2-}, r_{j}^{3-}\right)
$$

And

$$
\tilde{R}_{j}^{+}=\operatorname{Max}_{1 \leq i \leq n}\left\{\tilde{R}_{i j}\right\}=\left(\operatorname{Max}_{1 \leq i \leq n}\left\{r_{j}^{1}\right\}, \operatorname{Max}_{1 \leq i \leq n}\left\{r_{j}^{2}\right\}, \operatorname{Max}_{1 \leq i \leq n}\left\{r_{j}^{3}\right\}\right)=\left(r_{j}^{1+}, r_{j}^{2+}, r_{j}^{3+}\right)
$$

Step 4: The distance $d_{i}^{-}$and $d_{i}^{+}$of each alternative from $\tilde{R}_{i j}$ to $\tilde{R}_{j}^{-}$and $\tilde{R}_{j}^{+}$are computed. In order to perform a sensitivity analysis, different separation measures used in Fuzzy TOPSIS will be used, Vertex Method (Tadic et al., 2013; Tadić et al., 2014; Jaksić et al., 2016) and Extensions of Euclidean and Hamming distance based on the Hausdorff metric have been developed and applied in fuzzy TOPSIS (Grzegorzewski, 2004; Jaksić et al., 2016).

\section{A novel extension of Spearman distance}

We propose a novel methodology to estimate the distance between two triangular numbers based on the Spearman distance extension and the Hausdorff metric.

Definition 6: For any two subsets $U$ and $W$ of a Banach space $Z$ the Hausdorff metric is

$$
d_{H}(U, W)=\max \left\{\sup _{u \in U} \inf _{w \in W}|u-w|, \sup _{w \in W} \inf _{u \in U}|u-w|\right\}
$$

If $Z=\mathrm{R}$ and $U=\left[u_{1}, u_{2}\right]$ and $W=\left[w_{1}, w_{2}\right]$ are intervals, then (9) reduces to

$$
d_{H}(U, W)=\max \left\{\left|u_{1}-w_{1}\right|,\left|u_{2}-w_{2}\right|\right\}
$$


Novel Distance Measure in Fuzzy TOPSIS to Improve Ranking Process: An Application to the Spanish Grocery Industry

Definition 7: For any two subsets $U=\left\{u_{1}, \ldots, u_{n}\right\}$ and $W=\left\{w_{1}, \ldots, w_{n}\right\}$; $U, W \in \mathrm{R}$ the Spearman distance is

$$
D_{s}=\sum_{i=1}^{n}\left(u_{i}-w_{i}\right)^{2}
$$

The distance $d_{i}^{-}$and $d_{i}^{+}$of each alternative from $\tilde{R}_{i j}$ to $\tilde{R}_{j}^{-}$and $\tilde{R}_{j}^{+}$are computed, from the Spearman distance based on the Hausdorff metric. From equations (10) and (11) Spearman distance extension is obtained.

$$
d_{i}^{-}=d\left(\tilde{R}_{i j}, \tilde{R}_{j}^{-}\right)=\frac{1}{2} \sum_{j=1}^{J}\left[\max \left(\left|r_{i j}^{1}-r_{j}^{1-}\right|,\left|\left(r_{i j}^{2}-r_{j}^{2-}\right)\right|\right)^{2}+\max \left(\left|r_{i j}^{2}-r_{j}^{2-}\right|,\left|\left(r_{i j}^{3}-r_{j}^{3-}\right)\right|\right)^{2}\right]
$$

and

$$
d_{i}^{+}=d\left(\tilde{R}_{i j}, \tilde{R}_{j}^{+}\right)=\frac{1}{2} \sum_{j=1}^{J}\left[\max \left(\left|r_{i j}^{1}-r_{j}^{1+}\right|,\left|\left(r_{i j}^{2}-r_{j}^{2+}\right)\right|\right)^{2}+\max \left(\left|r_{i j}^{2}-r_{j}^{2+}\right|,\left|\left(r_{i j}^{3}-r_{j}^{3+}\right)\right|\right)^{2}\right]
$$

For $i=1, \ldots, n ; j=1, \ldots, J$

Our work allows to increase the number of methodologies to compute the distance between two fuzzy numbers when applying fuzzy TOPSIS, thus widening the set of available rankings for the decision maker.

Step 5: Finally, closeness coefficient $C C_{i}$ of alternative $A_{i}$ is defined as:

$$
C C_{i}=\frac{d_{i}^{-}}{d_{i}^{-}+d_{i}^{+}} \quad i=1, \ldots, n
$$

Step 6: Ranking. Obviously, $0 \leq C C_{i} \leq 1$, where $i=1, \ldots, n . C C_{i}=1$ and therefore, alternative $A_{i}$ is the ideal solution. On the contrary, $C C_{i}=0$ denotes that $A_{i}$ is the anti-ideal solution. An alternative $A_{i}$ is closer to the ideal solution and farther from the anti-ideal solution as $C C_{i}$ approaches 1. From here, the alternatives are ranked according to closeness coefficients and then the best alternative is selected.

\section{Case study}

As a complement to our research, we develop an application of both the well-known and the novel proposed methodologies to evaluate the financial performance of the main Spanish grocery store companies with net sales exceeding 1500 million Euros. Companies are subject to evaluation by using the data sets of the years 2010 to 2014. The financial data used in this analysis are extracted from balance sheet, income statement and cash-flow statement on SABI database by Bureau Van Dijk. 
Javier Reig-Mullor, David Pla-Santamaria, Ana García-Bernabeu, Francisco Salas-Molina

In Figure 1, the hierarchical structure for the general form of the performance evaluation is stated. The overall goal at the first level determines the best financial performance. At the second level, 23 financial ratios are classified in five criteria: (i) five liquidity ratios, (ii) five solvency ratios, (iii) four ratios for activity, (iv) four profitability analyses and finally (v) five growth analyses.

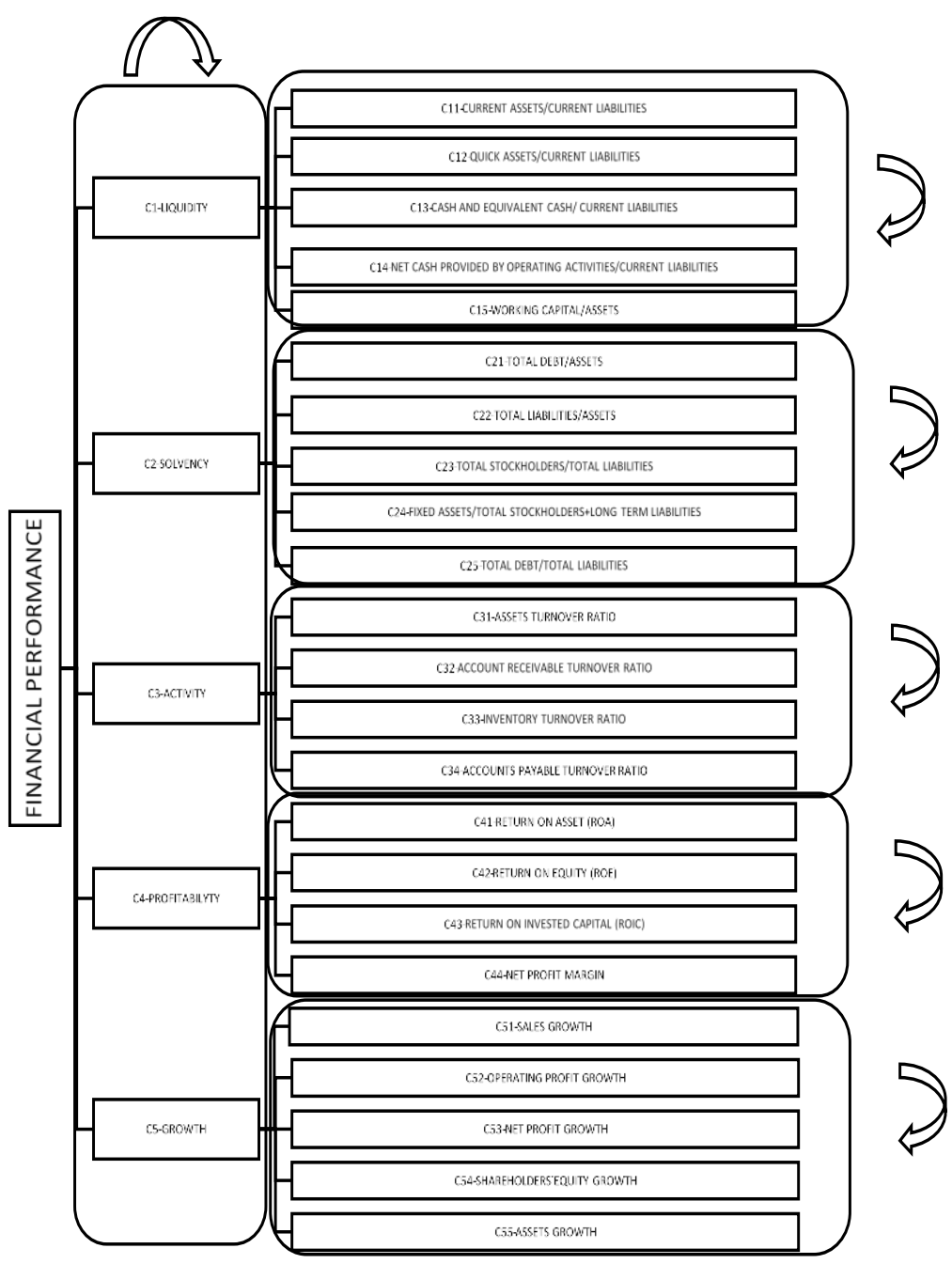

Figure 1. Decision Hierarchy Structure 
Novel Distance Measure in Fuzzy TOPSIS to Improve Ranking Process: An Application to the Spanish Grocery Industry

The step by step process is as follows:

firm.

Step 1. Conduct financial analysis. Financial ratios are computed for each

Step 2. Perform expert evaluation.

(1) Three decision makers from different areas evaluate the relevance of these ratios with the help of questionnaires. Since different stakeholders inside and outside the firm have diverse objectives and expectations, the financial analysis must be carried out from different perspectives. Financial indicators have different significance for diverse users (Ertuğrul and Karakaşoğlu, 2009). For example, CEOs are mainly interested in activity and growth indicators while investors and shareholders focus their vision on profitability ratios, and creditors are mostly worried about financial leverage.

(2) One decision maker, accounting and financial expert, evaluates the interdependences among criteria and subcriteria.

Linguistic scale in Table 1 is used by decision makers to represent their opinion.

Step 3. Apply FANP. FANP is applied to improve the decision process by reducing the uncertainty and vagueness of the decision maker's subjective judgment. By using equation (3), the experts' judgements on the relative importance among criteria and the associated subcriteria are obtained. The opinions are presented as a fuzzy pairwise comparison matrix. Table 2 shows the fuzzy pairwise aggregate matrix obtained from the experts' judgements on the relative importance among the five liquidity subcriteria.

Table 2. Fuzzy pairwise comparison matrix for subcriteria of liquidity

\begin{tabular}{l|lllll}
\multicolumn{2}{l}{$C 11$} & $C 12$ & $C 13$ & $C 14$ & $C 15$ \\
\hline$C 11$ & 1 & $(1,1.82,4)$ & $(0.2,0.35,1)$ & $(0.17,0.23,0.33)$ & $(0.33,0.63,1)$ \\
$C 12$ & $(0.25,0.55,1)$ & 1 & $(0.25,0.33,0.5)$ & $(0.17,0.28,0.5)$ & $(0.25,1.1,3)$ \\
$C 13$ & $(1,2.88,5)$ & $(2,3,4)$ & 1 & $(0.33,0.63,1)$ & $(1,3.48,8)$ \\
$C 14$ & $(3,4.3,6)$ & $(2,3.56,6)$ & $(1,1.59,3)$ & 1 & $(1,3.48,8)$ \\
$C 15$ & $(1,1.59,3)$ & $(0.33,0.91,4)$ & $(0.13,0.29,1)$ & $(0.13,0.29,1)$ & 1
\end{tabular}

Similarly, from the accounting and financial expert's opinion, the fuzzy pairwise comparison matrices for interdependence relationships among criteria and subcriteria are built.

Step 4. Elicit criteria weights. Criteria weights are derived from fuzzy pairwise comparison matrices on the relative importance. We apply the nonlinear program developed by Mikhailov [see equation (4)] to obtain the weight for each 
Javier Reig-Mullor, David Pla-Santamaria, Ana García-Bernabeu, Francisco Salas-Molina

criterion $\left(w_{i c i}\right)$ and subcriterion $\left(w_{i c i j}\right)$. These weights correspond to the application of the FAHP method.

Therefore, the normalized weight vector for the five criteria is obtained as follows,

$W_{i c}=(0.11,0.08,0.29,0.38,0.14)$ and $\lambda^{*}=0,43$

In the case of dependent relationships, the matrix of interdependent relationships must be developed for criteria $\left(W_{d c}\right)$ and for each one of the subcriteria $\left(W_{d c i}\right)$, by applying the non linear program developed by Mikhailov.

The normalized weights of the liquidity can be computed as follows,

$W_{d c}$ (liquidity $)=(0.23,0.46,0.17,0.14)$ and $\lambda^{*}=0,67$

The local weights of $\left(W_{c}\right)$ can be obtained by multiplying the matrix of interdependence relationships $\left(W_{d c}\right)$ by the weights of criteria with independent relationships $\left(W_{i c}\right)$.

$$
\begin{aligned}
& W_{c}=W_{d c} \times W_{i c} \\
& W_{c}=\left[\begin{array}{ccccc}
0 & 0.44 & 0.42 & 0.17 & 0.14 \\
0.23 & 0 & 0.29 & 0,17 & 0.19 \\
0.46 & 0.18 & 0 & 0.55 & 0.47 \\
0.17 & 0.25 & 0.17 & 0 & 0.19 \\
0.14 & 0,13 & 0.12 & 0.12 & 0
\end{array}\right] \times\left[\begin{array}{l}
0.33 \\
0.12 \\
0.11 \\
0.10 \\
0.34
\end{array}\right]=\left[\begin{array}{l}
0.17 \\
0.19 \\
0.39 \\
0.17 \\
0.08
\end{array}\right]
\end{aligned}
$$

In a similar way, the local weights of subcriteria $W_{c i}$ can be obtained by

$W_{c i}=W_{d c i} \times W_{i c i} \quad i=1, \ldots n$

Finally, the global weights $W$ are obtained by multiplying the local weights of the criteria $W c$ by the local weights of the associated subcriteria $\left(W_{c i}\right)$.

All weights obtained are shown in Table 3.

Table 3. Local weights, global weights of each criteria (financial ratios)

\begin{tabular}{|l|l|l|l|l|l|l|c|}
\hline \multirow{2}{*}{$C_{i}$} & $w_{i c i}$ & \multirow{2}{*}{$w_{c i}$} & $C_{i j}$ & $w_{i c i j}$ & $w_{c i j}$ & $\begin{array}{l}\text { FAHP } \\
\left(w_{i c i} \times w_{i c i j}\right)\end{array}$ & $\begin{array}{l}\text { FANP } \\
\left(w_{c i} \times w_{c i j}\right)\end{array}$ \\
\hline \multirow{3}{*}{$\mathrm{C}_{1}$} & \multirow{3}{*}{0.32} & \multirow{3}{*}{0.17} & $\mathrm{C}_{11}$ & 0.11 & 0.26 & 0.04 & 0.04 \\
\cline { 4 - 8 } & & $\mathrm{C}_{12}$ & 0.08 & 0.24 & 0.03 & 0.04 \\
\cline { 4 - 8 } & & $\mathrm{C}_{13}$ & 0.29 & 0.22 & 0.09 & 0.04 \\
\cline { 3 - 8 } & & $\mathrm{C}_{14}$ & 0.38 & 0.06 & 0.12 & 0.01 \\
\hline & & $\mathrm{C}_{15}$ & 0.13 & 0.23 & 0.04 & 0.04 \\
\hline
\end{tabular}


Novel Distance Measure in Fuzzy TOPSIS to Improve Ranking Process: An Application to the Spanish Grocery Industry

\begin{tabular}{|c|c|c|c|c|c|c|c|}
\hline \multirow{5}{*}{$\mathrm{C}_{2}$} & \multirow{5}{*}{0.12} & \multirow{5}{*}{0.19} & $\mathrm{C}_{21}$ & 0.26 & 0.25 & 0.03 & 0.05 \\
\hline & & & $\mathrm{C}_{22}$ & 0.18 & 0.28 & 0.02 & 0.05 \\
\hline & & & $\mathrm{C}_{23}$ & 0.14 & 0.17 & 0.02 & 0.03 \\
\hline & & & $\mathrm{C}_{24}$ & 0.08 & 0.13 & 0.01 & 0.02 \\
\hline & & & $\mathrm{C}_{25}$ & 0.33 & 0.18 & 0.04 & 0.03 \\
\hline \multirow{4}{*}{$\mathrm{C}_{3}$} & \multirow{4}{*}{0.11} & \multirow{4}{*}{0.39} & $\mathrm{C}_{31}$ & 0.29 & 0.31 & 0.03 & 0.12 \\
\hline & & & $\mathrm{C}_{32}$ & 0.12 & 0.29 & 0.01 & 0.11 \\
\hline & & & $\mathrm{C}_{33}$ & 0.44 & 0.29 & 0.05 & 0.11 \\
\hline & & & $\mathrm{C}_{34}$ & 0.15 & 0.11 & 0.02 & 0.04 \\
\hline \multirow{4}{*}{$\mathrm{C}_{4}$} & \multirow{4}{*}{0.10} & \multirow{4}{*}{0.17} & $\mathrm{C}_{41}$ & 0.15 & 0.44 & 0.02 & 0.07 \\
\hline & & & $\mathrm{C}_{42}$ & 0.13 & 0.13 & 0.01 & 0.02 \\
\hline & & & $\mathrm{C}_{43}$ & 0.38 & 0.16 & 0.04 & 0.03 \\
\hline & & & $\mathrm{C}_{44}$ & 0.34 & 0.27 & 0.04 & 0.05 \\
\hline \multirow{5}{*}{$\mathrm{C}_{5}$} & \multirow{5}{*}{0.34} & \multirow{5}{*}{0.09} & $\mathrm{C}_{51}$ & 0.20 & 0.33 & 0.07 & 0.03 \\
\hline & & & $\mathrm{C}_{52}$ & 0.35 & 0.19 & 0.12 & 0.02 \\
\hline & & & $\mathrm{C}_{53}$ & 0.26 & 0.23 & 0.09 & 0.02 \\
\hline & & & $\mathrm{C}_{54}$ & 0.08 & 0.14 & 0.03 & 0.01 \\
\hline & & & $\mathrm{C}_{55}$ & 0.10 & 0.10 & 0.04 & 0.01 \\
\hline
\end{tabular}

Step 5. Normalize values for Fuzzy TOPSIS. Normalization of the obtained values is performed by using an equation for each year.

$$
v_{i j}=\frac{e_{i j}}{\sqrt{\sum_{j=1}^{J} e_{i j}^{2}}}, j=1,2, \ldots, J ; i=1,2, \ldots, n
$$

Then, the triangular numbers $\tilde{V}_{i j}=\left(v_{i j}^{1}, v_{i j}^{2}, v_{i j}^{3}\right)$ can be obtained by using equation (5). In this way, the weighted normalized matrix is formed by multiplying each value with their weights using equation (6).

Step 6. Determine solutions $\tilde{R}^{-}$and $\tilde{R}^{+}$. Values are elicited by taking the maximum and minimum value for each criterion using equations (7) and (8).

Step 7. Separation measure. The distance of each alternative from $\tilde{R}^{-}$and $\tilde{R}^{+}$is calculated. The shortest distance from $d_{i}^{+}$and the farthest distance from $d_{i}^{-}$ are computed [see equations (12)-(13)].

Step 8. Compute the closeness coefficients. Through equation (14) the closeness coefficients $\left(C C_{i}\right)$ are obtained. 
Javier Reig-Mullor, David Pla-Santamaria, Ana García-Bernabeu, Francisco Salas-Molina

Aggregation of the results for period 2010-2014 is displayed in Table 4 providing an insight into the overall ranking of the grocery store companies.

Table 4. $C C_{i}$ and rank for the period 2010-2014 for FANP/ fuzzy TOPSIS

\begin{tabular}{|l|l|r|r|r|r|r|r|r|}
\hline & \multicolumn{6}{|c|}{ FANP-FUZZY TOPSIS (DISTANCE MEASURES) } \\
\cline { 2 - 10 } & \multicolumn{2}{|c|}{ VERTEX } & \multicolumn{2}{c|}{ HAMMING } & EUCLIDEAN & \multicolumn{2}{|c|}{ SPEARMAN } \\
\hline & $C C i$ & Rank & $C C i$ & Rank & $C C i$ & Rank & $C C i$ & Rank \\
\hline MERCADONA & 0.891 & 1 & 0.602 & 1 & 0.875 & 1 & 0.980 & 1 \\
\hline CARREFOUR & 0.265 & 6 & 0.305 & 6 & 0.313 & 5 & 0.172 & 5 \\
\hline DIA & 0.313 & 4 & 0.331 & 4 & 0.315 & 4 & 0.174 & 4 \\
\hline ALCAMPO & 0.331 & 2 & 0.371 & 2 & 0.357 & 2 & 0.236 & 2 \\
\hline LIDL & 0.297 & 5 & 0.311 & 5 & 0.296 & 6 & 0.150 & 6 \\
\hline CONSUM & 0.327 & 3 & 0.352 & 3 & 0.333 & 3 & 0.199 & 3 \\
\hline EROSKI & 0.238 & 7 & 0.229 & 7 & 0.234 & 8 & 0.085 & 8 \\
\hline SUPERCOR & 0.192 & 8 & 0.202 & 8 & 0.244 & 7 & 0.094 & 7 \\
\hline
\end{tabular}

As shown in Table 4, if we compare fuzzy TOPSIS (distance method) results, different company rankings are obtained. The use of a novel distance measure, a Spearman distance extension based on the Hausdorff metric, improves the sensitivity of results and offers the decision maker a new alternative for fuzzy TOPSIS.

\section{Conclusion}

The increasing uncertainty and complexity of the global market has led to a rise in the information flow, making the measurement of efficiency more difficult. In today's context, classical measures diminish their soundness and new approaches are needed. This study proposes a novel fuzzy MCDM approach to increase the information available to the analyst. We apply several methodologies together with our novel approach to evaluate the financial performance of the eight largest companies in the Spanish grocery store sector over years 2010-2014. This sector is characterized by a high supply saturation in the market, which results in low operating margins and reduced creation of added value. This involves the need for a financial performance that guarantees the survival of the firm. The fuzzy MCDM approach proposed in this paper has been proven successful in other contexts and case studies. In our combination of FANP and fuzzy TOPSIS, we apply Mikhailov methodology leading to crisp weights, which offer advantages over fuzzy weights. Crisp weights allow the analyst to easily check the consistency of the expert's opinions through index $\lambda^{*}$. 
Novel Distance Measure in Fuzzy TOPSIS to Improve Ranking Process: An Application to the Spanish Grocery Industry

The application of FANP methodology in place of FAHP allows us to analyze the relationships among the different financial criteria and subcriteria considered. This is because FAHP technique only considers models where there is dependence among variables.

In the present study, we show the need to use different computational techniques in the separation measure of Fuzzy TOPSIS, since the results may vary according to the selected technique. Therefore, different alternatives should be available to improve the sensitivity of the analysis of the final result.

The case study has shown the advantages and applicability of our proposed method and has provided effective fuzzy MCDM tools which could be further applied to numerous problems in different fields of study. Further research includes (1) extending the model to nonfinancial performance and efficiency; (2) using other fuzzy MCDM ranking methods such as VIKOR or DEA to analyze soundness; (3) developing and applying new fuzzy versions of TOPSIS to other fuzzy MCDM ranking methods.

\section{REFERENCES}

[1] Afful-dadzie, E., Komínková Oplatková, Z. and Beltran Prieto, A. L. (2017), Comparative State-of-the-Art Survey of Classical Fuzzy Set and Intuitionistic Fuzzy Sets in Multi-Criteria Decision Making; International Journal of Fuzzy Systems, 19, 726-738;

[2] Chai, J., Liu, J. N. K. and Ngai, E. W. T. (2013), Application of DecisionMaking Techniques in Supplier Selection: A Systematic Review of Literature; Expert Systems with Applications, 40(10), 3872-3885;

[3] Chen, J.-F., Hsieh, H.-N. and Do, Q. H. (2015), Evaluating Teaching Performance Based on Fuzzy AHP and Comprehensive Evaluation Approach; Applied Soft Computing, 28, 100-108;

[4] Ertuğrul, İ. And Karakaşoğlu, N. (2009), Performance Evaluation of Turkish Cement Firms with Fuzzy Analytic Hierarchy Process and TOPSIS Methods; Expert Systems with Applications, 36(1), 702-715;

[5] Grzegorzewski, P. (2004), Distances between Intuitionistic Fuzzy Sets and/or Interval-Valued Fuzzy Sets Based on the Hausdorff Metric; Fuzzy Sets and Systems, 148(2), 319-328;

[6] Jaksić, M., Moljević, S., Aleksić, A., Misita, M., Arsovski, S., Tadić, D. and Mimović, P. (2016), Fuzzy Approach in Ranking of Banks According to Financial Performances; Mathematical Problems in Engineering, vol 2016, 11 pages; 
Javier Reig-Mullor, David Pla-Santamaria, Ana García-Bernabeu, Francisco Salas-Molina

[7] Javanbarg, M. B., Scawthorn, C., Kiyono, J. and Shahbodaghkhan, B. (2012), Fuzzy AHP-based Multicriteria Decision Making Systems Using Particle Swarm Optimization; Expert Systems with Applications, 39(1), 960-966;

[8] Liang, G.-S. (1999), Fuzzy MCDM Based on Ideal and Anti-Ideal Concepts; European Journal of Operational Research, 112(3), 682-691;

[9] Mardani, A., Jusoh, A. and Zavadskas, E. K. (2015), Fuzzy Multiple Criteria Decision-Making Techniques and Applications - Two Decades Review from 1994 to 2014; Expert Systems with Applications, 42(8), 4126-4148; [10] Mikhailov, L. (2003), Deriving Priorities from Fuzzy Pairwise Comparison Judgements; Fuzzy Sets and Systems, 134(3), 365-385;

[11] Rezaie, K., Ramiyani, S. S., Nazari-Shirkouhi, S. and Badizadeh, A. (2014), Evaluating Performance of Iranian Cement Firms Using an Integrated Fuzzy AHP-VIKOR Method; Applied Mathematical Modelling, 38(21-22), 50335046 ;

[12] Saaty, T. L. (1980), The Analytic Hierarchy Process. New York, McGrawHill Inc;

[13] Saaty, T. L. (1996), Decision-making with Dependence and Feedback: The Analytic Network Process. Pittsburgh, PA: RWS Publications;

[14] Sansalvador, M. E. and Brotons, J. M. (2017), The Application of Owas in Expertise Processes: The Development of a Model for the Quantification of Hidden Quality Costs; Economic Computation and Economic Cybernetics Studies and Research, ASE Publishing, 51(3), 73-90;

[15] Tadić, D., Aleksić, A., Stefanović, M. and Arsovski, S. (2014), Evaluation and Ranking of Organizational Resilience Factors by Using a Two-Step Fuzzy AHP and Fuzzy TOPSIS; Mathematical Problems in Engineering, vol 2014, 13 pages;

[16] Tadic, D., Gumus, A. T., Arsovski, S., Aleksic, A. and Stefanovic, M. (2013), An Evaluation of Quality Goals by Using Fuzzy AHP and Fuzzy TOPSIS Methodology; Journal of Intelligent and Fuzzy Systems, 25(3), 547-556;

[17] Tavana, M., Zareinejad, M., Di Caprio, D. and Kaviani, M. A. (2016), An Integrated Intuitionistic Fuzzy AHP and SWOT Method for Outsourcing Reverse Logistics; Applied Soft Computing Journal, 40, 544-557;

[18] Wang, Y. J. (2014), The Evaluation of Financial Performance for Taiwan Container Shipping Companies by Fuzzy TOPSIS; Applied Soft Computing Journal, 22, 28-35;

[19] Yu, M., Keng, I. and Chen, H. (2015), Measuring Service Quality via a Fuzzy Analytical Approach; International Journal of Fuzzy Systems, 17(March), 292-302;

[20] Zadeh, L. A. (1965), Fuzzy Sets; Information and Control, 8(3), 338-353; 